\title{
Stimulation of the Locus Ceruleus Modulates Signal-to-Noise Ratio in the Olfactory Bulb
}

\author{
- Laura C. Manella, Nicholas Petersen, and Christiane Linster \\ Computational Physiology Laboratory, Department of Neurobiology and Behavior, Cornell University, Ithaca, New York 14850
}

\begin{abstract}
Norepinephrine (NE) has been shown to influence sensory, and specifically olfactory processing at the behavioral and physiological levels, potentially by regulating signal-to-noise ratio $(\mathrm{S} / \mathrm{N})$. The present study is the first to look at NE modulation of olfactory bulb $(\mathrm{OB})$ in regards to $\mathrm{S} / \mathrm{N}$ in vivo. We show, in male rats, that locus ceruleus stimulation and pharmacological infusions of NE into the $\mathrm{OB}$ modulate both spontaneous and odor-evoked neural responses. $\mathrm{NE}$ in the $\mathrm{OB}$ generated a non-monotonic dose-response relationship, suppressing mitral cell activity at high and low, but not intermediate, NE levels. We propose that NE enhances odor responses not through direct potentiation of the afferent signal per se, but rather by reducing the intrinsic noise of the system. This has important implications for the ways in which an animal interacts with its olfactory environment, particularly as the animal shifts from a relaxed to an alert behavioral state.
\end{abstract}

Key words: modulation; noise; noradrenaline; olfactory; signal

\section{Significance Statement}

Sensory perception can be modulated by behavioral states such as hunger, fear, stress, or a change in environmental context. Behavioral state often affects neural processing via the release of circulating neurochemicals such as hormones or neuromodulators. We here show that the neuromodulator norepinephrine modulates olfactory bulb spontaneous activity and odor responses so as to generate an increased signal-to-noise ratio at the output of the olfactory bulb. Our results help interpret and improve existing ideas for neural network mechanisms underlying behaviorally observed improvements in near-threshold odor detection and discrimination.

\section{Introduction}

Norepinephrine (NE) has been implicated in modulating signalto-noise ratio $(\mathrm{S} / \mathrm{N})$ in a variety of sensory systems (Waterhouse et al., 1990, 1998; McLean and Waterhouse, 1994; Aston-Jones et al., 2000; Devilbiss and Waterhouse, 2004; Devilbiss et al., 2006; Hirata et al., 2006; Moxon et al., 2007). The olfactory bulb (OB) is the first central network in the olfactory sensory pathway and is heavily innervated by noradrenergic fibers from the locus ceruleus (LC; for review, see Aston-Jones et al., 2000; Sara, 2009).

Several lines of evidence suggest that NE may influence $S / N$ in the OB. Behavioral experiments show that NE in the OB modu-

\footnotetext{
Received July 17, 2017; revised 0ct. 10, 2017; accepted 0ct. 17, 2017.

Author contributions: L.C.M., N.P., and C.L. designed research; L.C.M. and N.P. performed research; L.C.M., N.P., and C.L. analyzed data; L.C.M. and C.L. wrote the paper.

This work was supported by NIH/NIDCD Grant DC008702. We thank Dr. Thomas Cleland and Matthew Einhorn for designing the recording and odor stimulation system. This article was prepared while L.C.M. was employed at Cornell University. The opinions expressed in this article are the author's own and do not reflect the view of the National Institutes of Health, the Department of Health and Human Services, or the United States government. The authors declare no competing financial interests.

Correspondence should be addressed to Dr. Christiane Linster, Department of Neurobiology and Behavior, Cornell University, Mudd Hall, 215 Tower Road, Ithaca NY 14850. E-mail: CL243@cornell.edu.

DOI:10.1523/JNEUROSCI.2026-17.2017

Copyright $\odot 2017$ the authors $\quad 0270-6474 / 17 / 3711605-11 \$ 15.00 / 0$
}

lates the ability to detect and discriminate odors at concentrations below normal thresholds (Escanilla et al., 2010, 2012; Linster et al., 2011). Data from brain slice experiments show that $\mathrm{NE}$ leads to a simultaneous reduction in mitral cell spontaneous activity and an increase in mitral cell responsiveness to olfactory nerve stimulation (Hayar et al., 2001; Nai et al., 2010, 2012). When implemented in a computational model of the OB, these cellular modulations produce a net effect of increasing S/N (Linster et al., 2011; de Almeida et al., 2015), thereby implying the presence of a neural mechanism underlying this behavioral reduction of odor thresholds. Activation of NE receptors also influences various forms of short- and long-term plasticity in $\mathrm{OB}$ synapses, as evidenced by olfactory learning in neonatal (for review, see Moriceau et al., 2009) and adult rodents (Doucette et al., 2007; Mandairon et al., 2008; Shea et al., 2008; Linster et al., 2011; Devore and Linster, 2012; Manella et al., 2013). Although the brain slice data provided mechanisms to propose a computational model of $\mathrm{S} / \mathrm{N}$ regulation, we here present the first in vivo evidence for enhancement of $\mathrm{S} / \mathrm{N}$ at the $\mathrm{OB}$ output.

Within the glomerular layer of the $\mathrm{OB}$, olfactory sensory neurons form synapses onto OB output neurons [mitral/tufted (MT) cells] as well as local interneurons (periglomerular and external 
tufted cells). Glomerular layer interneurons modulate MT cell activity, which is then further processed in a deeper layer of the $\mathrm{OB}$, primarily by lateral inhibitory interactions with granule cell interneurons. Computations performed by bulbar neural networks have been described in detail (Cleland and Linster, 2005; Tan et al., 2010; Cleland, 2010). LC projections have been shown to target both the glomerular and deeper layers of the OB, with layer-specific distributions of noradrenergic receptor subtypes. Most previous analyses of NE effects in the OB have focused on NE modulation of mitral and granule cells (Linster et al., 2011; de Almeida et al., 2015; Li et al., 2015). However, a recent experiment by Eckmeier and Shea (2014) used imaging of the surface of the dorsal $\mathrm{OB}$ to show a direct and persistent reduction of sensory neuron input in response to LC stimulation. This effect was blocked by topical application of $\alpha$ - and $\beta$-adrenergic receptor antagonists, suggesting a functional effect of NE in the glomerular layer as well.

To relate these behavioral and slice physiological experiments to an in vivo model, we recorded single units from the OB MT cell layer, pairing odor stimulation with either local infusions of noradrenergic agents or electrical stimulation of the LC. We found that NE modulates mitral cell spontaneous activity, and increased both the number and amplitude of significant odor responses. An overall increase in $\mathrm{S} / \mathrm{N}$ was observed in response to LC stimulation; however, rather than arising from a combination of inhibition and excitation of mitral cells as previously suggested (Escanilla et al., 2010), the effect depended primarily on the suppression of spontaneous activity. Pharmacological manipulations further demonstrated that the effects of LC stimulation are at least partially mediated within the OB. These results, in conjunction with data from other laboratories (Eckmeier and Shea, 2014) make a clear case for how perceptual S/N modulation can occur at the first level of olfactory processing.

\section{Materials and Methods \\ Animals}

Adult male Long-Evans hooded rats (RRID:RGD_1302656; 275-350 g) were obtained from Charles River Laboratories. Ninety-eight rats total were used, 35 in Experiment 1, 37 in Experiment 2, and 26 in Experiment 3. Rats were double-housed and maintained with Purina rat chow and water ad libitum on a $12 \mathrm{~h}$ light/dark cycle. Experiments were performed during the dark cycle. All procedures followed NIH guidelines under the supervision of the Cornell University Institutional Animal Care and Use Committee and an approved animal care protocol.

\section{Surgery}

Anesthesia was induced with $5 \%$ isoflurane in a stream of oxygen $(1 \mathrm{~L} / \mathrm{min})$ through a Narishige anesthesia mask. Rats were then placed into a stereotaxic apparatus (Narishige Scientific Instruments) and maintained with $1-2 \%$ isoflurane in oxygen throughout the experiment. Viscous lidocaine $(2 \%)$ was used as a local anesthetic before exposure of the skull via scalpel incision. A large craniotomy was made over the OB. For stimulation experiments, a craniotomy was also drilled over the locus ceruleus (AP $2.0 \mathrm{~mm}$ posterior from lambda and $\mathrm{ML} \pm 1.2 \mathrm{~mm}$ from the midline). A piezoelectric monitor was strapped around the animal's chest to monitor breathing cycles. This respiration signal was used to trigger odor delivery upon inspiration for experiments requiring odor delivery.

\section{Electrophysiological recordings}

One or two $2 \mathrm{M} \Omega$ tungsten, parylene-C-insulated, monopolar recording probes (A-M Systems) were used to record from putative MT cells of the $\mathrm{OB}$. Electrodes were lowered from the surface of the OB using a stereotaxic micromanipulator (David Kopf Instruments). The MT cell layer was located by finding a layer exhibiting respiration-locked spiking activity. Units $(5000 \times$ amplification, filtered from $600 \mathrm{~Hz}$ to $6 \mathrm{kHz}, 20 \mathrm{kHz}$
Table 1. Odor dilutions of $1 \mathrm{~Pa}$ vapor partial pressure

\begin{tabular}{ll}
\hline Odor name & Percentage v/v dilution \\
\hline Butyl acetate & 0.0218 \\
Hexanal & 0.0222 \\
Butanol & 0.0208 \\
Propyl butyrate & 0.0522 \\
Propanoic acid & 0.0332 \\
Methyl 2-furoate & 0.2472 \\
\hline
\end{tabular}

sampling rate) were recorded; data were digitized and transferred to the computer using a CED Power1401 and Spike2 software (Cambridge Electronic Design).

\section{Electrical stimulation of the locus ceruleus}

A $1 \mathrm{M} \Omega$ tungsten, parylene-C-insulated, monopolar stimulation probe (A-M Systems) was placed in the LC (AP $2.0 \mathrm{~mm}$ posterior from lambda and $\mathrm{ML} \pm 1.2 \mathrm{~mm}$ from the midline) under stereotaxic guidance. The LC was located by adjusting the electrode angle from vertical to $\sim 12^{\circ}$ posterior, and lowering the electrode while recording under unit-recording amplifier settings. The LC was identified by finding characteristic broad and slow $(0-2 \mathrm{~Hz})$ tonic activity and a phasic response to tail pinch (Bouret and Sara, 2004). DV coordinates ranged from $\sim 4.1$ to $6 \mathrm{~mm}$ ventral at the above angle from the surface of the brain (variance due to electrode/head angle). Once LC recording was verified, the electrode was connected to a constant current stimulus isolation unit (Grass model PSIU6) controlled by a Grass S88 stimulator (Grass Technologies). During the experiment, 1, 2, 3, or $5 \mathrm{~Hz}(100 \mu \mathrm{s}, 100 \mu \mathrm{A})$ pulses were delivered to the LC while unit activity was recorded from the OB.

\section{Drugs}

Noradrenergic drugs were dissolved into $0.9 \%$ saline solution and then infused directly into the main $\mathrm{OB}(2.5 \mathrm{~mm}$ depth from the surface of the brain; $6 \mu \mathrm{l}$, delivered at $1 \mu \mathrm{l} / \mathrm{min}$ ) using a 33 gauge cannula attached to an infusion pump. L-(-)-norepinephrine $(+)$ bitartrate salt monohydrate was diluted to $1,10,100$, or $1000 \mu \mathrm{M}$ concentrations, aliquoted, and frozen. Drug mixtures also were made using $1000 \mu \mathrm{M}$ NE mixed with specific NE receptor antagonists: the $\alpha_{1}$ adrenergic receptor antagonist prazosin hydrochloride ( $1 \mathrm{~mm}$; Sigma-Aldrich), the $\alpha_{2}$ adrenergic receptor antagonist yohimbine hydrochloride (2 mM; MP Biomedical), and the $\beta$ adrenergic receptor antagonist alprenolol hydrochloride ( $120 \mathrm{~mm}$; Sigma-Aldrich). Dosages of NE and antagonists were based on previous studies from our laboratory, which showed significant perceptual effects of these drugs (Mandairon et al., 2008; Escanilla et al., 2010, 2012).

\section{Odor presentations}

An odor mixture was used to increase the probability of finding odorresponsive MT cells. Within this odor mixture, each odorant was first diluted to approximate a vapor-phase partial pressure of $1 \mathrm{~Pa}$ in mineral oil (Table 1), then added to the mixture, and the mixture was serially diluted to emit 0.1 and $0.01 \mathrm{~Pa}$. To deliver the odor, a custom built olfactometer was used. Clean, charcoal-filtered, humidified air was pumped through the mask (rat anesthesia mask, Narishige Scientific Instruments) constantly at $1 \mathrm{~L} / \mathrm{min}$. A second constant airstream was routed through a selected bottle of odorized mineral oil. For odor delivery, the airstream in the nose mask was switched from the clean airstream to the odorized airstream; this strategy prevented a mechanical odordelivery stimulus artifact and ensured that the odor delivered was at a stable concentration. Odor presentations lasted $2 \mathrm{~s}$, and were separated by at least $30 \mathrm{~s}$.

\section{Experiment 1: effect of LC stimulation on MT spontaneous activity}

In this experiment, MT cell spontaneous activity was recorded during $180 \mathrm{~s}$ trials. From 60 to $120 \mathrm{~s}$, LC was electrically stimulated at a particular rate (see above; Fig. 1A). In some animals, more than one stimulation frequency was tested, in which case the above trials were separated by at 
A

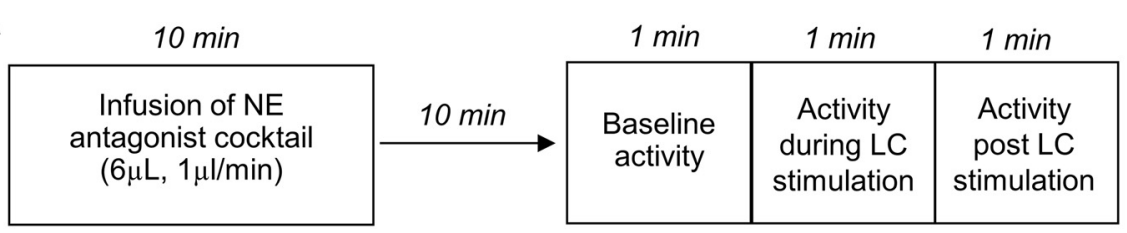

B

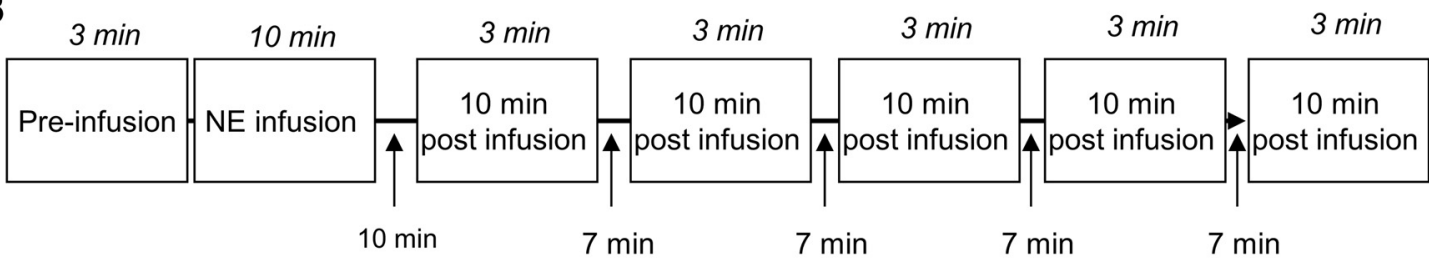

C

Trial block

\begin{tabular}{|c|c|c|}
\hline $0.01 \mathrm{~Pa}$ odor & $0.1 \mathrm{~Pa}$ odor & $1 \mathrm{~Pa}$ odor \\
$2 \mathrm{~s}$ & $2 \mathrm{~s}$ & $2 \mathrm{~s}$ \\
6 trials & 6 trials & 6 trials \\
$30 \mathrm{~s} \mathrm{ITI}$ & $30 \mathrm{~s}$ ITI & $30 \mathrm{~s} \mathrm{ITI}$ \\
\hline
\end{tabular}

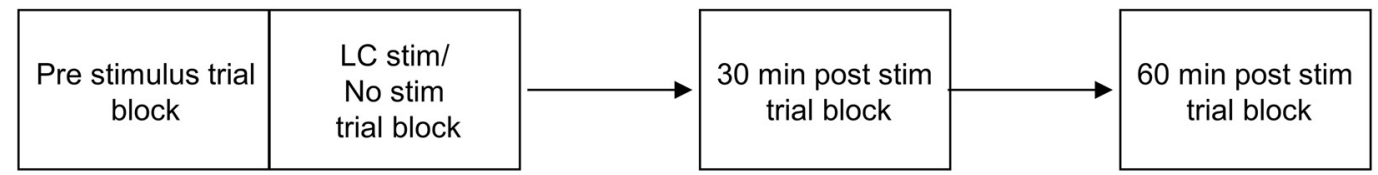

D

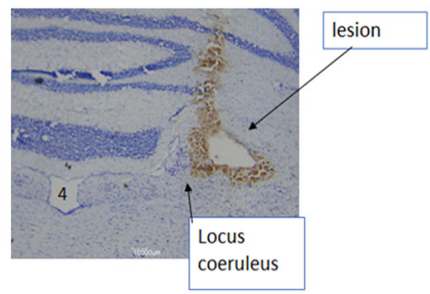

Figure 1. Experimental design. $A$, In Experiment 1, we recorded data in three chunks: 1 min of baseline activity, 1 min with $\mathrm{LC}$ stimulation at a specific frequency (1, 2, 3, 4, or $5 \mathrm{~Hz})$, and 1 min post-LC stimulation. This was sometimes repeated for different $L C$ stimulation frequencies, always in increasing order and separated by at least 30 min. $\boldsymbol{B}$, In Experiment 2 , we tested how local bulbar infusions of NE (or NE paired with NE antagonists) modulated mitral/tufted cell responses. We recorded 3 min segments before infusion, then 10, 20,30, 40, and 50 min after the end of the infusion. C, In Experiment 3, each odor trial block consisted of three sets of six odor stimulations lasting $2 \mathrm{~s}$ and separated by $30 \mathrm{~s}$. There were four trial blocks: pre-LC stimulation, with continuous $5 \mathrm{~Hz} \mathrm{LC}$ stimulation, and 30 and $60 \mathrm{~min}$ post- $\mathrm{LC}$ stimulation. $\boldsymbol{D}$, Example of histological verification of $\mathrm{LC}$ stimulation electrode.

least $30 \mathrm{~min}$. In control experiments, either saline or a mixture of three $\mathrm{NE}$ antagonists $\left(\alpha_{1}, \alpha_{2}\right.$, and $\beta$ receptor antagonists) was infused into the OB 20 min before the beginning of the recording session.

\section{Experiment 2: effect of local NE infusions on MT spontaneous activity.}

Baseline MT cell recordings (180 s) were obtained, followed by an infusion of either NE or a combination of NE and two (of the three) receptor antagonists (concentrations above). Twenty minutes after the start of infusion, six $3 \mathrm{~min}$ recording trials were obtained at $10 \mathrm{~min}$ intertrial intervals (Fig. $1 B$ ) to see the progression of the drug effects. The $20 \mathrm{~min}$ wait after infusions mimics our established behavioral protocols (Mandairon et al., 2008; Escanilla et al., 2010, 2012). Due to drug being present for an indeterminate amount of time, this was the last/only experiment run on a given animal.

\section{Experiment 3: effect of LC stimulation of MT odor responses} In this experiment, each trial block (Fig. 1C) consisted of three sets of six odor exposures at each of the following concentrations consecutively: $0.01,0.1$, and $1 \mathrm{~Pa}$. For each odor trial within this block, the odor expo- sure lasted $2 \mathrm{~s}$ and inter-odor intervals were $30 \mathrm{~s}$. Before LC stimulation, one trial block was used to determine baseline odor responsiveness. Next, there was one trial block where each odor trial was paired with a $5 \mathrm{~s}$ of 5 $\mathrm{Hz} \mathrm{LC}$ stimulation commencing at $2.5 \mathrm{~s}$ before the onset of odor exposure and lasting until $0.5 \mathrm{~s}$ after the end of odor exposure, similar to previous studies (Shea et al., 2008; Eckmeier and Shea, 2014). Finally, two poststimulation trial blocks followed at 30 and $60 \mathrm{~min}$ after the start of the LC stimulation trial block (Fig. 1C).

\section{Histological verification of electrode placement}

At the end of successful experiments, a large positive DC electrical current (10 s duration, $15 \mathrm{~mA}$ ) was run through each electrode (recording in the $\mathrm{OB}$ and stimulation in the LC) to generate an electrolytic lesion (Fig. $1 D$ ). Rats then were perfused with $10 \%$ neutral buffered formalin. Brains were extracted and later sectioned at $40 \mu \mathrm{m}$ and stained with cresyl violet to stain for cell bodies. Locations of the electrodes were verified, and if recording electrodes in the main $\mathrm{OB}$ were not in the mitral cell layer or if stimulating electrodes were not in the LC, data were excluded from future analysis. 


\section{Experimental design and analysis}

Spike sorting

Single units were extracted post hoc using Spike2 spike sorting software. Spike templates were derived from raw data, after which appropriate templates were selected and refined. To refine these waveforms, principal components analysis was used to group features of the waveforms onto a three-dimensional plot. Interspike interval distributions were used to assess the quality of each single unit. Multiunit and questionable single unit data were excluded from analysis.

\section{Data analysis}

Spontaneous activity. After spike extraction, we calculated spontaneous activity by averaging the firing rates of individual neurons during $60 \mathrm{~s}$ epochs before, during, and after LC stimulation or NE infusion. To test for the overall effect of LC stimulation or NE infusion on spontaneous activity, we used a mixed model ANOVA with average firing rate of all recorded MT cells as the dependent variable, recording epoch (pre-, during, and post-manipulation) as a within-subjects factor and stimulation frequency or NE dosage as between-subject factors, $\alpha$ was set to 0.05 . This was followed by ANOVA testing for effects of recording epoch at each stimulation frequency individually with $\alpha$ set to 0.0125 to account for multiple comparisons, or for individual NE dosages with $\alpha$ set to 0.01 to account for multiple comparisons. When testing the effect of local NE receptor blockade on LC stimulation we used an ANOVA to test for effect of recording epoch after saline or antagonist infusions ( $\alpha$ was set to 0.025 to account for multiple comparisons). To test for the role of individual NE receptors we used an ANOVA with drug (saline, $\alpha_{1}+\alpha_{2}$ blocker, $\alpha_{1}+\beta$ blocker, $\alpha_{2}+\beta$ blocker) as between-subjects factors and recording epoch (pre and post) as within-subjects factor with $\alpha$ set to 0.05 . To assess whether activity during pre- and post-recording was different for individual drug groups this was followed by individual ANOVAs for each drug group with $\alpha$ set to 0.0125 to account for multiple comparisons. To assess how many individual neurons exhibited significant modulation (change in firing rate) in response to LC stimulation or NE infusion we compared pre- and post-manipulation firing rates using average rate over $1 \mathrm{~s}$ bins as a dependent variable for individual neurons using a $t$ test $(\alpha=0.05)$. The degree of modulation [modulation index (MI)] of individual neurons was calculated as the difference between during and before (or after and before) divided by the sum. To test whether the degree of modulation was correlated with initial firing rates, we calculated Pearson's $r$ between modulation indices and prestimulation neuronal firing rates, with $\alpha$ set to 0.05 .

Odor responses. After spike extraction, we first tested for significant odor responses in individual cells by comparing the firing rate pre-odor application to that post-odor application (post-epoch started at odor delivery) over six trials (Student's $t$ test, $\alpha=0.05$ ) for a given neuron. The degree of responsiveness to odorants was calculated as the difference between pre-odor and post-odor rates divided by the sum [odor response index (RI)]. To test for the effect of LC stimulation on odor responses we used a repeated-measures ANOVA with the odor RI under control and LC stimulation conditions as a within-subjects factor and odor concentration as a between-subjects factor, with $\alpha$ set to 0.05 . $\mathrm{S} / \mathrm{N}$ was calculated as the ratio between firing rates during odor application and the sum of firing rates during odor application and during spontaneous activity (Hasselmo et al., 1997). Modulation of S/N by LC stimulation was assessed using a mixed model ANOVA with $\mathrm{S} / \mathrm{N}$ under control or LC stimulation conditions as within-subjects factor and odor concentration as between-subjects factor $(\alpha=0.05)$. Correlations between spontaneous rates and modulation index, spontaneous activity and odor response modulation indices, and odor responses under both conditions were calculated using Pearson's $r$ with $\alpha$ set to 0.05 .

\section{Results \\ Experiment 1 \\ LC stimulation modulates spontaneous activity of MT cells in vivo}

We recorded data from 123 cells in 35 rats; of these recordings, 63 stable MT units were used to test the effect of LC stimulation on spontaneous firing and $27 \mathrm{U}$ were used to test whether the observed effect depended on bulbar NE receptors. Baseline spontaneous activity varied between 0.7 and $80 \mathrm{~Hz}$, with a mean of $19 \pm 1.4 \mathrm{~Hz}$.

LC stimulation affected spontaneous activity of individual MT cells: 55 MT cells ( $87 \%$ of cells) significantly changed firing rate in response to LC stimulation at any frequency, with the highest numbers of significant changes elicited by $5 \mathrm{~Hz}$ stimulation (74\% of cells recorded during $5 \mathrm{~Hz}$ stimulation; Fig. 2A,B). A repeated-measures analysis yielded a significant effect of the interaction between recording period (pre-, during, and post-LC stimulation) and LC stimulation frequency on overall rate $\left(F_{(2,186)}=\right.$ 3.187; $p=0.001)$; both $1 \mathrm{~Hz}\left(F_{(2,19)}=6.320 ; p=0.008\right)$ and $5 \mathrm{~Hz}$ $\left(F_{(2,50)}=6.008 ; p=0.005\right)$. Although we observed both increased and decreased rates in response to LC stimulation, the average effect of LC stimulation on spontaneous firing was a decrease: there was a mean rate of $17.6 \pm 1.4 \mathrm{~Hz}$ during prestimulation, $16.53 \pm 1.3$ $\mathrm{Hz}$ during and $15.3 \pm 1.27 \mathrm{~Hz}$ post-LC stimulation. Figure $2 \mathrm{~A}$ shows examples of spontaneous firing rate modulations with the proportion of modulated epochs after each stimulation frequency shown in Figure $2 B$. Figure 2, $C$ and $D$, shows a breakdown of modulation indices during poststimulation epochs (MI) by stimulation frequency. Overall the largest changes in firing rate were seen at $5 \mathrm{~Hz}$ stimulation, with both the most cells modulated and the strongest overall modulation (average of -0.355 and $0.244 \mathrm{MI}$ for decrease and increase, respectively). Although significantly modulated cells were found at each stimulation frequency both during and post-LC stimulation, when we directly compared overall firing rates during and after LC stimulation to baseline using all recorded cells, significant changes were observed at 1,3 , and $5 \mathrm{~Hz}$ LC stimulation during poststimulation epochs only $(p=0.008, p=0.003$, and $p=0.007$, respectively, using pairwise comparisons). Therefore, subsequent analyses will be performed on the period after LC stimulation (post-epoch) only unless otherwise noted.

\section{Spontaneous rate modulation is proportional to initial firing rate}

We then asked whether the magnitude of modulation by LC stimulation depended on the initial spontaneous activity of the neurons. Analyzing poststimulation epochs at all stimulation frequencies, we found that modulation by LC stimulation was significantly anticorrelated with initial firing rates, with low rates modulated up and high rates modulated down (Pearsons' $r=$ $-0.293 ; p=0.004$; Fig. 3). Overall these results show that initial firing rates of neurons help determine how LC stimulation influences spontaneous firing rate.

\section{Effect of LC stimulation depends on activation of bulbar NE receptors}

To verify that LC stimulation was affecting MT cells via direct action in the main $\mathrm{OB}$, we infused a mixture of $\alpha_{1}, \alpha_{2}$, and $\beta \mathrm{NE}$ antagonists or saline as control into the $\mathrm{OB}$ before LC stimulation (see Materials and Methods). We stimulated the LC at $5 \mathrm{~Hz}$, because we found the most dramatic changes in MT cells when stimulating at this frequency (Fig. 2B). We recorded from $34 \mathrm{MT}$ cells total and confirmed that $5 \mathrm{~Hz}$ LC stimulation significantly modulated overall MT cell spontaneous activity [effect of epoch (pre and post): $\left.F_{(1,21)}=6.083 ; p=0.022\right]$, whereas this effect was not observed in the presence of the NE antagonist mixture $\left(F_{(1,11)}=\right.$ $0.222 ; p=0.646$ ). Figure $4 B$ shows the distribution of modulation indices in the presence of the antagonist mixture (compare to Fig. $2 \mathrm{Div}$ ). These results indicate that observed effects of LC stimulation are at least partially mediated by activation of $\mathrm{OB}$ receptors. 
A
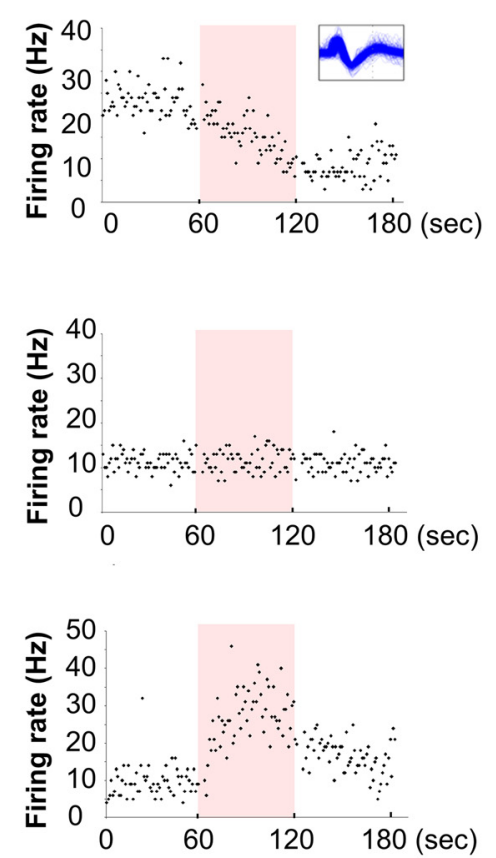

B

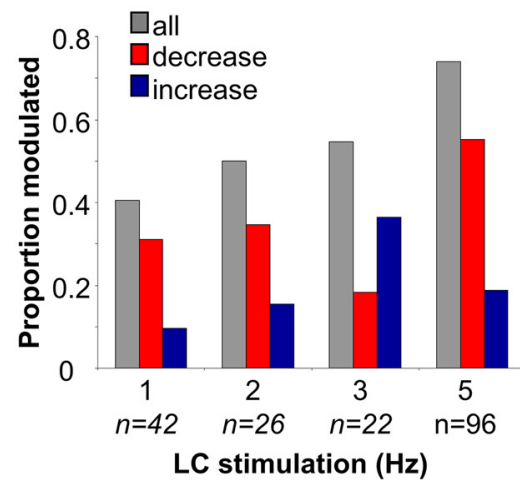

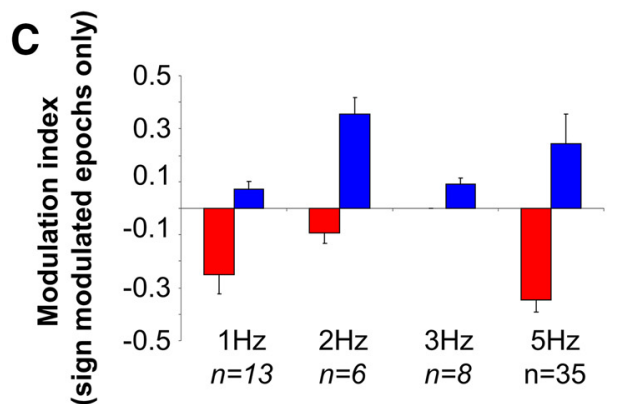

No sign modulation

Significant decrease

Significant increase

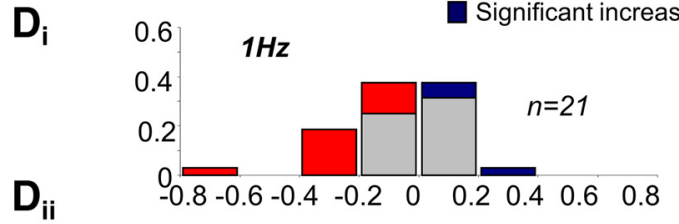

\section{(1)}

$D_{\text {iii }}$

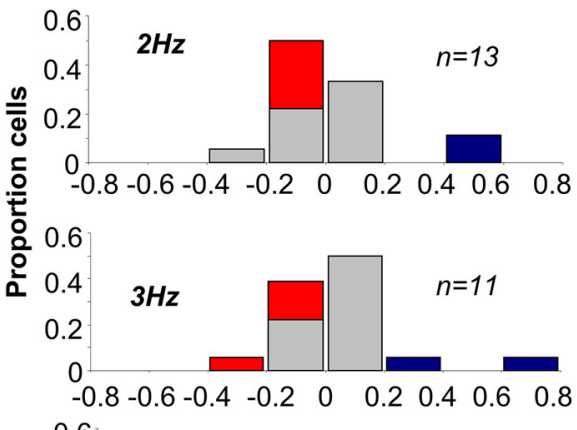

0.6

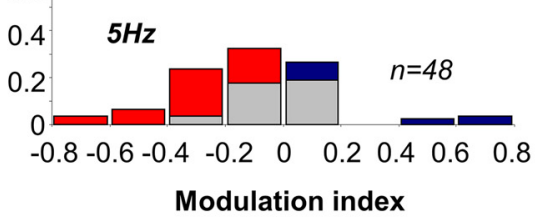

Figure 2. Modulation of spontaneous activity by LC stimulation. $\boldsymbol{A}$, Three examples of MT cells recordings, ones that decrease, do not change, or increase spontaneous activity in response to $5 \mathrm{~Hz}$ stimulation of LC. Each graph shows the firing rate recorded in 1 s intervals of a single cell over $180 \mathrm{~s}$. The shading indicates when $\mathrm{LC}$ electrical stimulation occurred, and the inset is an example of extracted spike shape. $B$, The graph shows the proportion of recorded neurons that were modulated by $L C$ stimulation at each stimulation frequency for both during and post-LC stimulation epochs. $\boldsymbol{C}$, The degree of modulation was a function of stimulation frequency. This graph shows the average amount that cells either decrease or increase because of different stimulation frequencies. $\boldsymbol{D}$, The graphs show the proportion of recorded cells exhibiting a range of modulation indices for each stimulation frequency (Di: $1 \mathrm{~Hz}$, Dii: $2 \mathrm{~Hz} ;$ Diii: $3 \mathrm{~Hz} ;$ Div: $5 \mathrm{~Hz}$ ) and both recording epochs. Note that both the degree of modulation and number of modulated cells changes non-monotonically as a function of stimulation frequency.

\section{Experiment 2}

Local NE infusions modulate spontaneous activity in a dose-dependent manner

A parallel set of recordings tested how local infusions of NE in the OB compared with LC stimulation. Baseline spontaneous activity was first recorded for a $180 \mathrm{~s}$ interval, followed by local infusion of $1,10,100$, or $1000 \mu \mathrm{M}$ NE followed by a series of $180 \mathrm{~s}$ recordings $10,20,30,40,50$, and $60 \mathrm{~min}$ after the end of the drug infusion (Fig. 1B). We recorded from $50 \mathrm{MT}$ cells in 37 rats (Fig. $5 A$ shows an example recording). Cells displayed spontaneous activities ranging between 1.2 and $45 \mathrm{~Hz}$ with an average of $10.6 \pm 1.3 \mathrm{~Hz}$. In the following analyses, only data from the 10 and $20 \mathrm{~min}$ post-drug recording epochs were included because at these time points stable recordings were obtained for all $50 \mathrm{MT}$ cells we recorded. A repeated-measures ANOVA with average firing rate as dependent variable, $\operatorname{drug}(0,1,10,100$, and $1000 \mu \mathrm{M}$
$\mathrm{NE}$ ) as between-subjects factor and recording epoch (pre-, 10 min after, and 20 min post-) as within-subjects factor yielded a significant effect of recording epoch $\left(F_{(2,44)}=11.380 ; p=0.001\right)$ as well as a significant interaction between recording epoch and $\operatorname{drug}\left(F_{(8,90)}=2.052 ; p=0.049\right)$. Interestingly, significant modulation of spontaneous activity at the $10 \mathrm{~min}$ and $20 \mathrm{~min}$ postdrug recording epochs was observed at the two lowest ( 1 and $10 \mu \mathrm{M})$ and the highest $(1000 \mu \mathrm{M})$ concentrations of NE. In contrast to LC stimulation, local infusions of NE into the OB produced almost exclusively reductions in spontaneous activity (Fig. $5 B, D$ ).

Blockade of $\alpha 1$ adrenergic receptors suppresses modulation of spontaneous activity in response to $\mathrm{NE}$

To test for the role of individual NE receptor types in modulation of spontaneous activity, we recorded data from an additional 33 putative MT cells. In these recordings, $1000 \mu \mathrm{M}$ NE was infused 
together with antagonists to two of three NE receptor types (see Materials and Methods). Data obtained with infusions of $1000 \mu \mathrm{M}$ NE reported above were reused in this analysis. ANOVA with drug $\left(1000 \mu \mathrm{M}\right.$ NE, $1000 \mu \mathrm{M} \mathrm{NE}+\alpha_{1}, \alpha_{2}$ antagonist, $1000 \mu \mathrm{M} \mathrm{NE}+\alpha_{1}, \beta$ antagonist, $1000 \mu \mathrm{M} \mathrm{NE}+\alpha_{2}, \beta$ antagonist) as between-subjects factor and recording epoch (pre-drug and 10 min post-drug) as within-subjects factor yielded a significant effect of recording epoch $\left(F_{(1,35)}=5.6\right.$; $p=0.024)$ as well as a significant interaction between drug and recording epoch $\left(F_{(3,35)}=4.909 ; p=0.006\right)$. Interestingly, the significant effect of recording epoch was present for rats infused with $1000 \mu \mathrm{M}$ $\operatorname{NE}\left(F_{(1,7)}=9.078 ; p=0.012\right)$ and 1000 $\mu \mathrm{M} \mathrm{NE}+\alpha_{2}+\beta$ antagonists $\left(F_{(1,9)}=\right.$ $12.469) ; p=0.011$, whereas no significant effect of epoch was found when $\alpha 1+\beta$ or $\alpha 1+\alpha 2$ receptors were blocked $\left(F_{(1,11)}=\right.$ $1.017 ; p=0.335$ and $F_{(1,8)}=1.201 ; p=$ $0.305)$. These data suggest that $\alpha_{1}$ receptor activation is necessary to mediate the modulation of MT cell spontaneous activity under these conditions.

\section{Experiment 3}

LC stimulation enhances odor responsiveness in MT cells

Experiment 3 tested NE modulation of odor-evoked responses of MT cells in the OB by LC stimulation (Fig. 1C). Based on our results from Experiment 1, we used $5 \mathrm{~s}$ of $5 \mathrm{~Hz}$ LC stimulation. To enhance chances to record from odor responsive mitral cells as well as to test for possible odor concentration-dependent effects, we used three concentrations (corresponding to vapor-phase partial pressures of $1,0.1$, and $0.01 \mathrm{~Pa}$ ) of a six-component odor mixture (Table 1). Note that we used low odor concentrations compared with experiments from other groups based on the idea that LC stimulation would enhance $\mathrm{S} / \mathrm{N}$ ratio in mitral cells when responding to close to threshold concentrations (Escanilla et al., 2010, 2012; Linster et al., 2011); odor concentrations used here are behaviorally relevant (Cleland et al., 2002).

We recorded from $54 \mathrm{MT}$ cells in 26 rats. Of these 54 cells, 31 presented with stable recordings long enough to complete recordings with at least two of three odor concentrations under control and experimental conditions. Eighteen of these 31 cells (58\%) displayed a significant response to odor stimulation with at least one of the three odor concentrations (comparison of pre-odor versus during odor activity; see Materials and Methods). When odors were applied during the block with $5 \mathrm{~Hz} \mathrm{LC}$ stimulation, 24 of 31 cells (77\%) significantly changed firing rate to at least one of the three odor concentrations (Fig. 6B). A repeated-measures ANOVA with odor RI (measure for amplitude of odor responses; see Materials and Methods) as the dependent variable, control or LC stimulation as the within-subjects factor and odor concentration as the between-subjects factor showed a significant effect of LC stimulation on odor response index $\left(F_{(1,83)}=7.264 ; p=0.009\right)$ but no interaction with odor concentration $\left(F_{(2,83)}=0.820 ; p=0.44\right.$, Wilk's lambda). Overall odor response amplitudes were significantly greater under LC stimulation conditions when all neural responses (odor responsepre-odor activity; including nonsignificant odor responders) were considered $\left(F_{(1,83)}=7.264 ; p=0.009=\right.$; Fig. $\left.6 C\right)$.
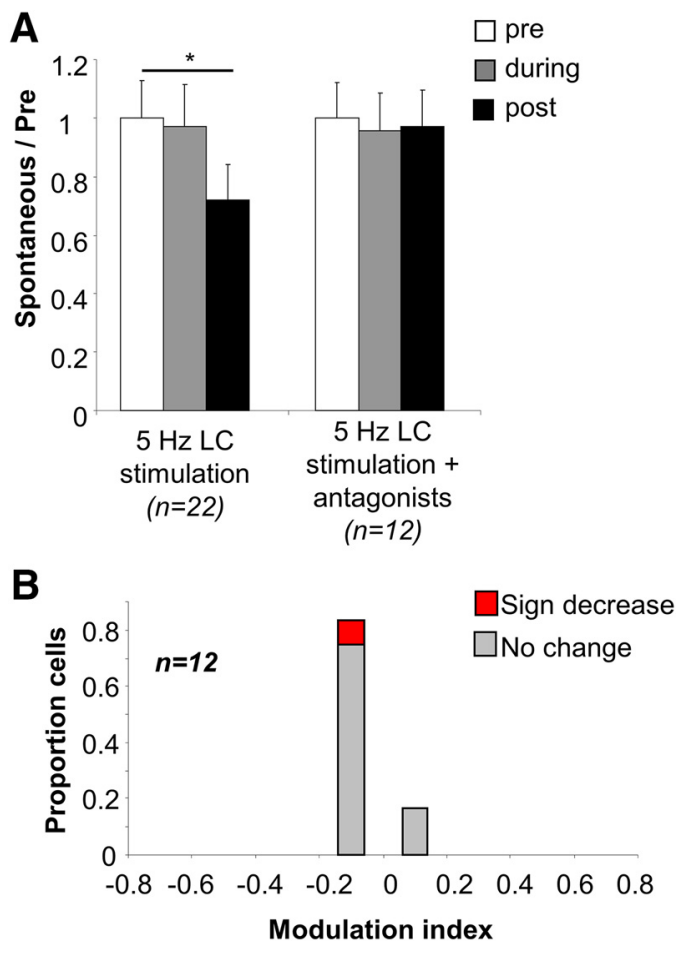

Figure 4. LC stimulation effects are blocked by local infusion of NE antagonists. $\boldsymbol{A}$, The graph shows the changes in MT spontaneous activity in response to $5 \mathrm{~Hz}$ LC stimulation in coordination with saline or NE antagonists infusions. These responses are normalized to the prestimulus activity. $\boldsymbol{B}$, The distribution of modulation indices in the presence of an NE antagonist mixture in response to $5 \mathrm{~Hz}$ stimulation shows very limited modulation of spontaneous activity.

As reported in previous experiments, MT cells responded with an increased or decreased firing rate to odor stimulation (Fig. $7 A$ ). Overall, the proportion of significant excitatory responses went up under LC stimulation conditions whereas the proportion of significant inhibitory responses went down. Figure $7 B$ shows the distribution of odor RIs under control (Fig. 7Bi) and LC stimulation (Fig. 7Bii) conditions. 
A

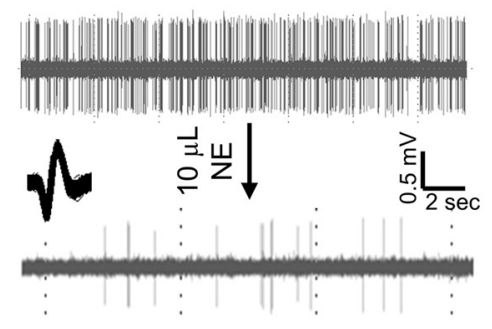

C

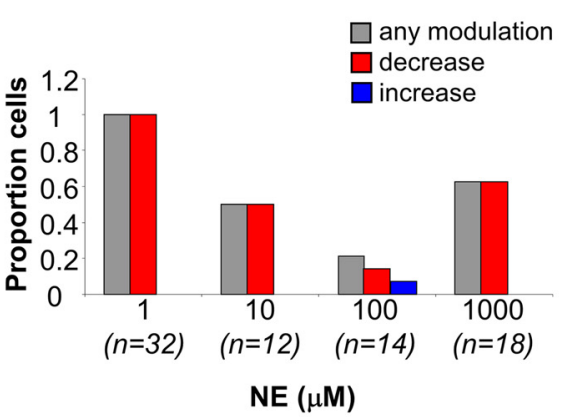

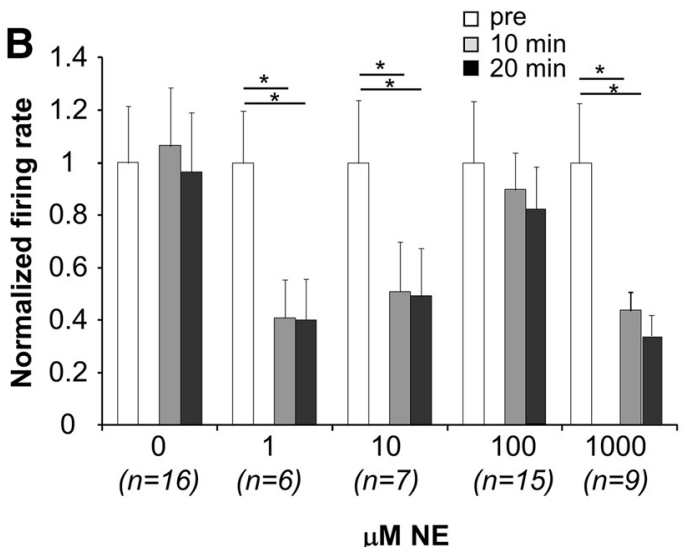

D

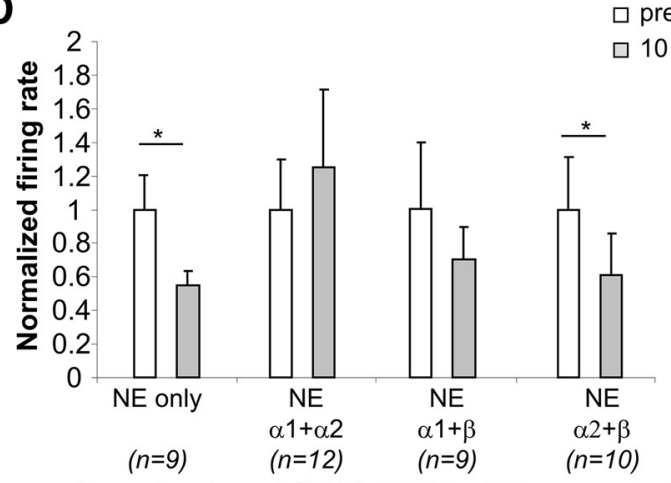

Drug treatment $(1000 \mu \mathrm{M} N E+N E$ antagonists $)$

Figure 5. Local infusions of NE into the $O B$ effect MT cell spontaneous activity. $A$, Example MT cell recorded in the $O B$ before and after $10 \mu$ I NE infusion. The top trace is spontaneous activity under control conditions, and the bottom trace is spontaneous activity $10 \mathrm{~min}$ after infusion of $1000 \mu \mathrm{M}$ NE into the OB. The inset is the extracted spike template. $\boldsymbol{B}$, The effect of NE depends on concentration. Firing rates are normalized to pre-infusion rates recorded at different time intervals after NE infusion. *Indicate epochs during which the rate was significantly modulated compared with the pre-infusion rate. $\boldsymbol{C}$, The proportion of cells modulated by local infusions of NE during both post-infusion recording epochs. In contrast to LC stimulation, modulation is almost exclusively decreases firing rates and follows a non-monotonic relationship with dosage. D. The average firing rates of MT cells 10 min after infusion of NE in concurrence with NE receptor antagonists, normalized to the pre-infusion rate. Note that the reduction of firing observed with $1000 \mu \mathrm{l} \mathrm{NE}$ is only apparent when $\alpha_{1}$ receptors in the $\mathrm{OB}$ are not blocked.
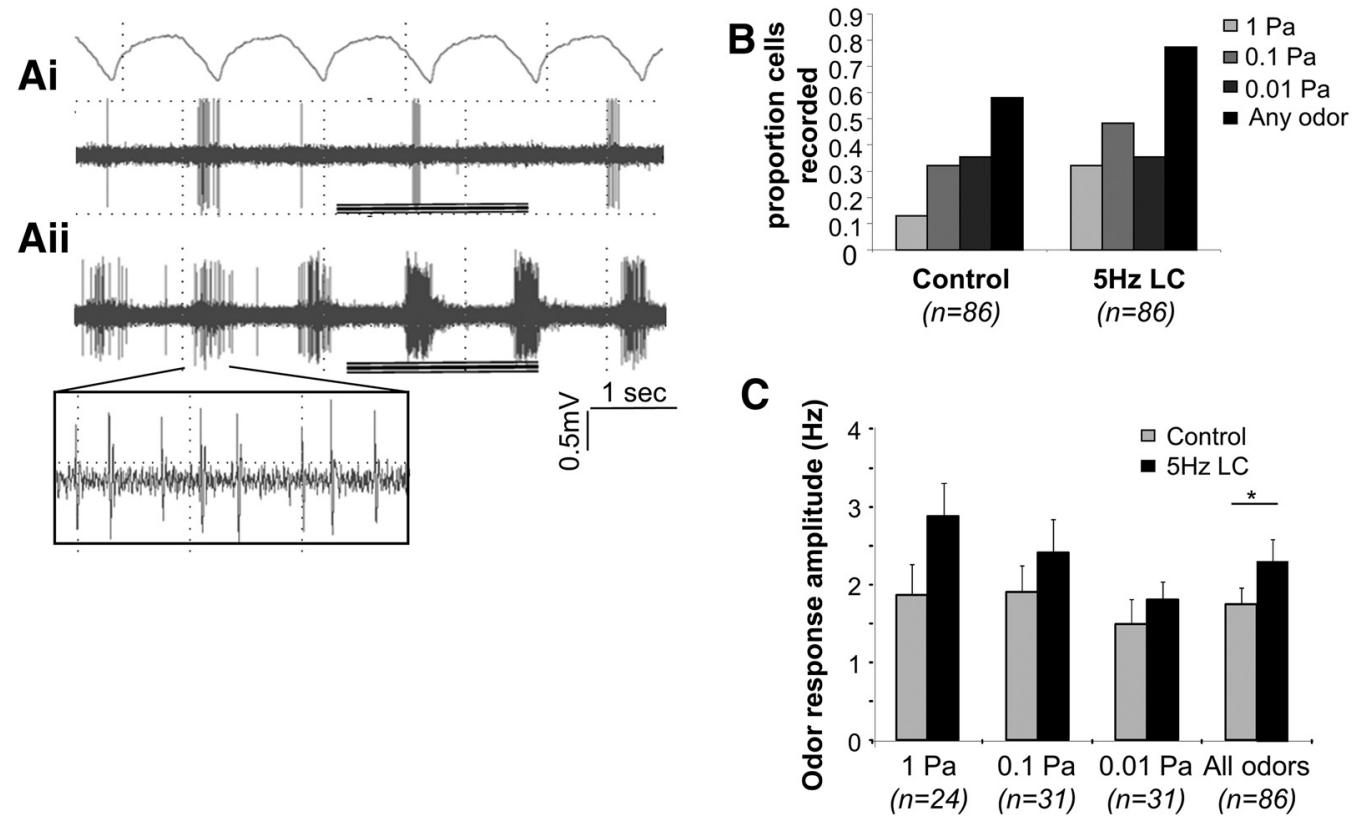

Figure 6. Modulation of odor responses by $\mathrm{L} C$ stimulation. $A$, Example MT odor response. The top trace is respiration. The middle trace is the activity of a recorded MT cell with odor application $(1 \mathrm{~Pa})$ indicated by the black line (Ai). The bottom trace is the response to the odor stimulation immediately after $5 \mathrm{~Hz} L \mathrm{~L}$ (stimulation (Aii). Inset, Higher resolution of the recorded action potentials. $B$, The distribution of odor responsive cells under each condition and odor concentration. $C$, The average odor response amplitudes across all recorded responses (significant and nonsignificant) at each odor concentration is shown here. 
A
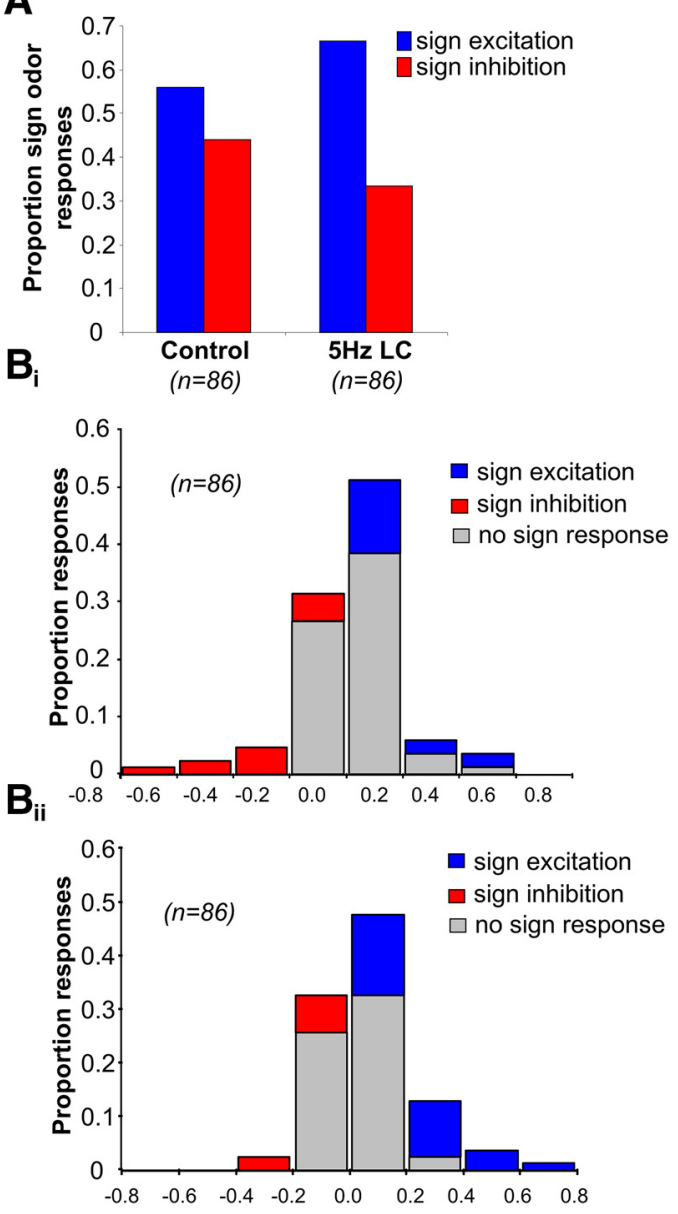

Figure 7. Modulation of odor responses by $5 \mathrm{~Hz} \mathrm{LC}$ stimulation. $\boldsymbol{A}$, The distribution of significant excitatory and inhibitory responses to odors (across concentrations) for each condition. LC stimulation increases the number of total responses and the relative proportion of excitatory responses specifically. $\boldsymbol{B}$, The proportion of odor responses within each range of odor response magnitude (RI) for control (Bi) and LC stimulation (Bii).

\section{LC stimulation increases $\mathrm{S} / \mathrm{N}$ during in response to odor stimulation}

Previous behavioral results strongly suggest a role of bulbar NE for modulation of $\mathrm{S} / \mathrm{N}$ in odor processing (Escanilla et al., 2010). We therefore used a classical definition for $\mathrm{S} / \mathrm{N}$ in sensory networks with $\mathrm{S} / \mathrm{N}$ = odor-response/spont + odor-response (Hasselmo et al., 1997). Analyzing data from all recorded odor stimulations (including nonsignificant responses), we found strong effects of LC stimulation on $\mathrm{S} / \mathrm{N}\left(F_{(1,82)}=5.063 ; p=0.028\right.$ with Wilk's lambda $)$, with significant effects of LC stimulation for $1 \mathrm{~Pa}\left(F_{(1,23)}=4.499 ; p=\right.$ $0.045)$ and $0.1 \mathrm{~Pa}\left(F_{(1,30)}=6.552 ; p=0.16\right)$ odor concentrations (Fig. 8).

\section{LC stimulation enhances odor responses through modulation of spontaneous activity}

LC stimulation affected the modulation of the spontaneous activity recorded $2 \mathrm{~s}$ before each odor stimulus in the same manner than that recorded with longer time intervals reported above (Fig. $9 A$; Pearson's $r=-302 ; p=0.005)$. Interestingly, the degree of LC modulation (MI) during odor stimulation was predictable from that during spontaneous activity (Pearson's $r=0.872 ; p=$ 0.001 ); this strongly suggests that there was no additional modulation of the odor response (Fig. 9B). As shown in Figure 9C, the odor response amplitude under LC stimulation conditions was

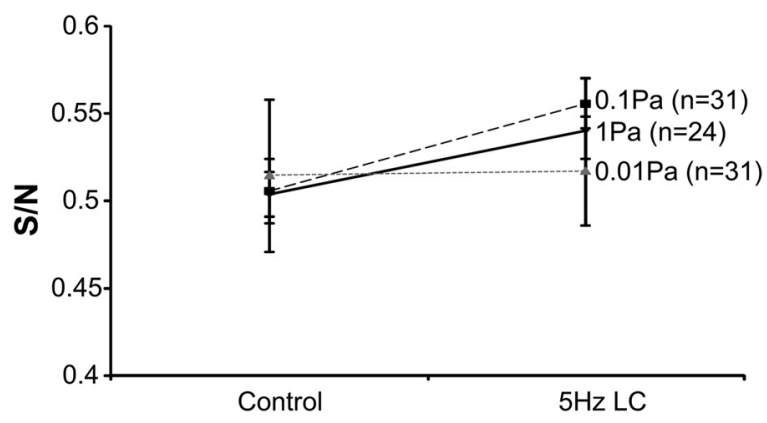

Figure 8. LC stimulation influences $S / N$. The average $S / N$ in the population of recorded mitral cells for all odors or individual concentrations for each experimental condition. As detailed in the main text, there is a significant increase of overall $S / N$ under $L C$ stimulation conditions.

consistently higher than that under control conditions. Under LC stimulation conditions, the magnitude of odor responses was significantly anticorrelated with spontaneous activity $(r=-0.260 ; p=$ 0.016 with Pearson's $r$ ), suggesting the low firing cells were more likely to respond with increased rates to odor stimulation and high firing cells were more likely to be inhibited. This relationship was not significant under control conditions $(r=-0.44 ; p=0.688$; Fig. $9 D)$. Together these data suggest that it was likely that because of overall decreased spontaneous activity by LC stimulation, odor responses were more likely to be detected without changing in absolute firing rate.

\section{Discussion}

The present experiments showed that noradrenaline modulates $\mathrm{OB}$ physiology in anesthetized rats. Electrical stimulation of the LC as well as NE pharmacological manipulations produced changes in spontaneous activity of MT cells in the OB. In experiments with electrical stimulation of the LC, the degree of spontaneous activity modulation was dependent on both LC stimulation frequency and MT cell baseline firing rate. Pharmacological controls using antagonists for $\mathrm{NE}$ receptors within the $\mathrm{OB}$ showed that activation of local $\mathrm{NE}$ receptors was necessary to see the effects of LC stimulation. Interestingly, and likely due to very little LC activity in anesthetized animals, antagonists by themselves did not have an effect on spontaneous activity.

We found a non-monotonic dose-response curve qualitatively similar between LC stimulation and direct infusion of NE on MT cell activity (Fig. 10). Medium dosages showed a much weaker effect than lower or higher dosages. We used commonly used stimulation frequencies and NE dosages, and as far we know ours is a first direct comparison between these two means of activating NE receptors. We showed that high dosages of NE (1000 $\mu$ l) correlate with the effect to $5 \mathrm{~Hz}$ tonic LC stimulation. This type of non-monotonic dose-response curve has been observed in many physiological and behavioral studies concerning manipulations of LC, NE and stress on behavior and physiological measures alike (Joëls et al., 2006; Sandi and Pinelo-Nava, 2007).

Importantly, this complex dose-dependent relationship of NE has also been shown in olfactory behavioral and brain slice physiology experiments (Nai et al., 2009; Escanilla et al., 2010). The non-monotonic response can possibly be attributed to the difference in receptor affinities and efficacies of adrenergic receptor subtypes locally in the OB (Escanilla et al., 2010, 2012; Linster et al., 2011). In these studies, differential receptor activation led to different ratios of excitation and inhibition in the circuit. We showed that spontaneous activity of MT cells was suppressed at 
A

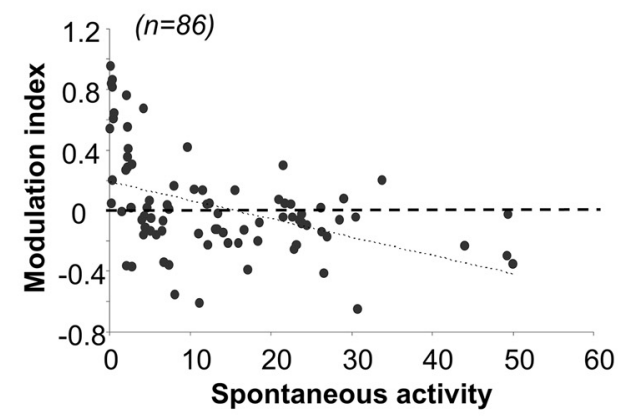

B

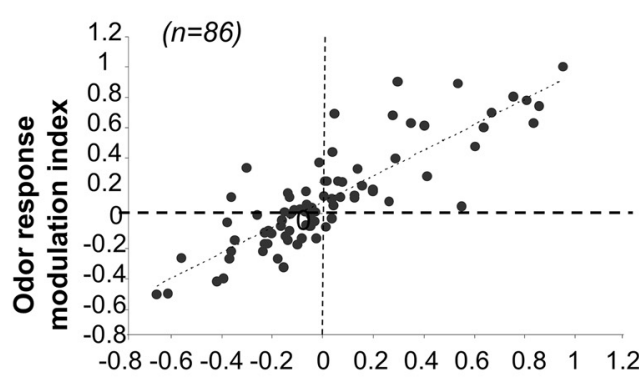

Spontaneous activity modulation index
C

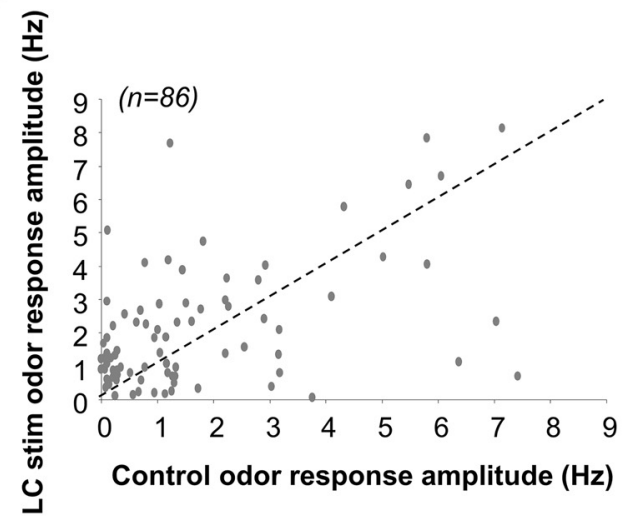

D

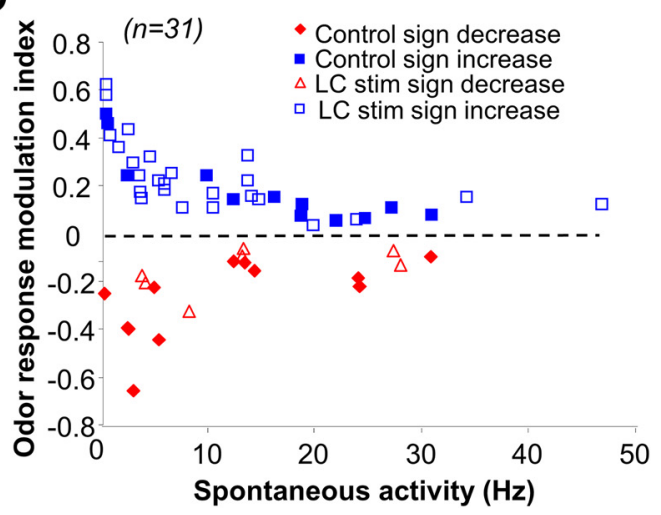

Figure 9. Correlation plots. A, Initial MT firing rates dictate how spontaneous activity during odor response recordings is modulated. The graph shows the degree of modulation by $5 \mathrm{~Hz} \mathrm{LC}$ stimulation observed during the pre-odor epoch as a function of spontaneous rate. $\boldsymbol{B}$, Spontaneous activity modulation correlates well with the modulation of odor responses by $\mathrm{LC}$ stimulation. The graph shows the modulation index during odor presentation epochs (MI) as a function of that during pre-odor epochs (MI). C, Absolute amplitudes of odor responses are consistently higher under $\mathrm{LC}$ stimulation than under control situation. The graph shows the absolute value of odor all odor responses during $\mathrm{LC}$ stimulation as a function of the absolute value of all odor responses under control conditions. $\mathbf{D}$, The degree of odor response modulation as a function of pre-odor spontaneous activity for control and LC conditions.

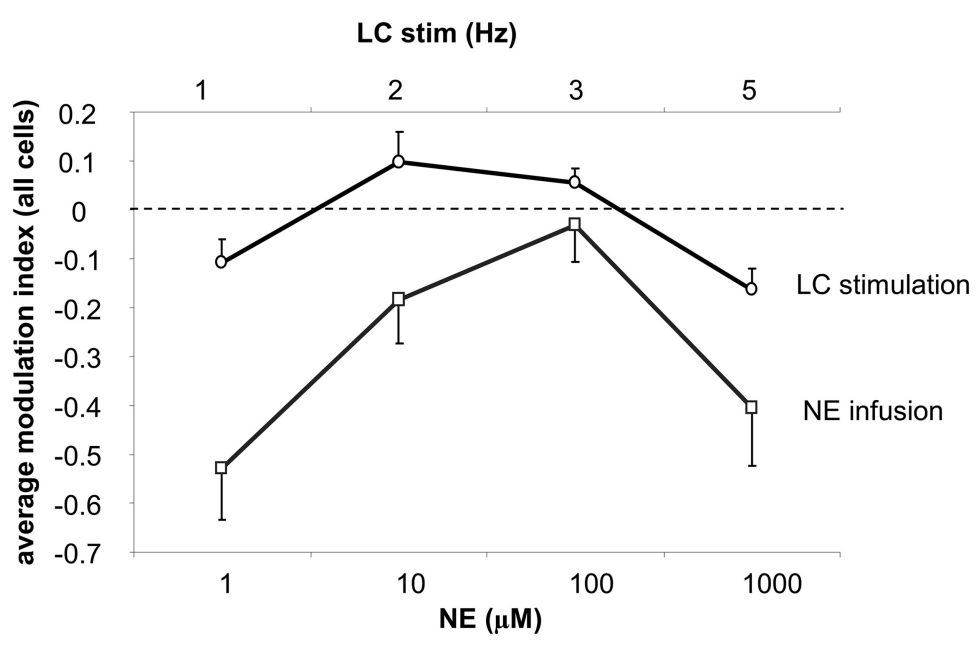

Figure 10. Comparison of $\mathrm{LC}$ stimulation and NE infusion on $\mathrm{OB}$ mitral/tufted cell spontaneous activity. The graph shows the average modulation index of all recorded cells (including those with nonsignificant modulation) as a function of LC stimulation frequency or NE infusion concentration. Note the non-monotonic dose-response curve in both conditions. LC stimulation either increases or decreases spontaneous firing rate depending on frequency, whereas NE infusion only decreases firing rates. tors in the OB (Fig. 5). We also observed significant increases of some MT cell firing rates with intermediate LC stimulation frequencies but not with intermediate $\mathrm{NE}$ dosages. This disparity could be attributed to differences in local concentrations of $\mathrm{NE}$ in response to LC stimulation (McLean, 1989) compared with whole-bulb NE concentration distributions in response to bulbar infusions. Alternatively or additionally, the change could have been mediated by extrabulbar effects of NE that feed into the OB in the case of LC stimulation.

Slice data suggest dual effects of $\alpha_{1}$ receptor modulation in the OB: activation of these receptors depolarizes granule cells and therefore enhances inhibitory tone onto mitral cells, as well as increases excitability in mitral cells directly. Computational modeling suggests that the above effects could act to enhance $\mathrm{S} / \mathrm{N}$ by sup-

low and high, but not intermediate LC stimulation frequencies or NE dosages, and thus there is likely a dynamic relationship between type(s) and degree of receptor activation. At high dosages of NE (1000 $\mu \mathrm{M}$, for instance), we showed that suppression in spontaneous activity was dependent upon activation of $\alpha_{1}$ recep- pressing mitral cell spontaneous activity via enhancement of inhibitory tone and increasing odor responses via enhanced mitral cell excitability (Escanilla et al., 2010; Linster et al., 2011). This enhanced S/N could underlie the improved detection thresholds we observed behaviorally (Escanilla et al., 2010). Other groups suggest 
an enhanced odor response independent of spontaneous activity, due to an increase in excitability in mitral cells (Jiang et al., 1996; Ciombor et al., 1999; Hayar et al., 2001). Here, we observed an increase in significant odor responses during activation of LC, but our analyses suggest that this increase was due to the modulation of the underlying spontaneous activity rather than an increase of odor responses per se as suggested by previous modeling studies (Escanilla et al., 2010; Linster et al., 2011; Fig. 9A). It is important to note that we used relatively low, behaviorally relevant odor concentrations, in contrast to other explorations of $\mathrm{OB}$ physiology [for example, our odor concentrations are 10-100X less than those used by Eckmeier and Shea (2014)]. We used tonic rather than phasic LC stimulation, which has been shown in other olfactory (Bouret and Sara, 2002) and sensory areas (AstonJones and Bloom, 1981; Bouret and Sara, 2004) to selectively enhance sensory responses. Again, differences in dosages as well as timing are likely to influence the effect that NE has on a brain area.

A previous behavioral study in the laboratory suggested that $\mathrm{NE}$ increases $\mathrm{S} / \mathrm{N}$ ratio (Linster et al., 2011). We here show that $\mathrm{S} / \mathrm{N}$ during odor stimulation was increased by LC stimulation, which could underlie increased odor detection capabilities, albeit with a different underlying mechanism than we originally proposed computationally (Linster et al., 2011). In our behavioral experiments the strongest effect of NE infusions were near the threshold for odor detection: rats infused with a high dosage of $\mathrm{NE}$ were capable of detecting odorants as low as $10^{-6} \mathrm{~Pa}$ vapor partial pressure compared with $10^{-2}$ vapor partial pressure odor detection in control animals (Escanilla et al., 2010, 2012). In the present experiments we did not observe a similar concentrationdependent effect on $\mathrm{S} / \mathrm{N}$. When comparing these results one must consider the fact that in the behavioral experiments we added NE into a system that was presumably already activated and contained some NE already. When blocking NE receptors, odor detection thresholds were considerably higher than in control animals, at concentrations more similar to the effects seen here. It is possible that our tonic stimulation replicated background noradrenergic tone, which enhances $\mathrm{S} / \mathrm{N}$ through suppressing background noise and subsequent unmasking of already present odor responses. However, this is likely not the whole story: phasic NE release through the LC could additionally mediate a direct enhancement of signal/odor responsiveness.

In an experiment similar to the one reported here but monitoring OB input rather than output, Eckmeier and Shea (2014) showed that LC stimulation produced a NE-dependent depression of spontaneous and odor-evoked input activity at the input layer to the OB. Because this experiment used calcium imaging to monitor presynaptic activity arriving from the olfactory nerve, it is likely that NE modulation of glomerular circuits is involved in this process. Specifically, NE excitation of external tufted cells, as reported in brain slice experiments (Zhou et al., 2016) could activate local inhibitory neurons, which act presynaptically to reduce olfactory nerve inputs (Aroniadou-Anderjaska et al., 2000; Ennis et al., 2001). Similar to the results reported here, Eckmeier and Shea (2014) showed a stronger effect on spontaneous than odor-evoked activity, resulting in reduced background levels of activity at the OB input layer.

The LC and NE are involved in behavioral state, vigilance, attention, and memory processes in various sensory and memory systems (Rajkowski et al., 1994; Aston-Jones et al., 2000; Bouret and Sara, 2002, 2004; Berridge and Waterhouse, 2003; Valentino and Van Bockstaele, 2008). In our study, we specifically chose tonic LC stimulation to mimic NE levels released through changes in be- havioral state by using protocols like those used by Shea et al. (2008), but unlike other studies that have used phasic LC stimulation (Bouret and Sara, 2002). It is possible that our high dosages of NE were correlated with the levels of NE released in the OB during these odor tasks, whereas our lower doses were analogous to a less active behavioral state. We observed lasting effects after the LC stimulation in Experiment 1, as reported previously in vivo (Shea et al., 2008; Eckmeier and Shea, 2014) and in vitro (Gire and Schoppa, 2008). In Experiment 3, we do see an immediate effect of LC stimulation on spontaneous activity (Fig. 9A) during the pre-odor epoch; however, in this experiment LC stimulation lasts over the course of several odor trials. Together with experiments from other groups this suggests that modulatory effects of LC activation may be delayed and long lasting, rather than being time-locked to specific bouts of LC activation. As such, the present study provides an insight into how state-dependent modifications in LC firing rates during different behavioral states affect odor processing in primary sensory areas in general. Given the altered state of neuromodulators due to anesthesia, we cannot directly compare the present results to data obtained in awake animals. Our results show a lack of effect of antagonists on MT cell activity, suggesting that the anesthetized state may correspond more closely to a "no NE" state in a behaving animal and our NE infusions mimic what happens in a behaving and motivated animal. Therefore, our study perhaps suggests that moderate arousal states may lead to enhanced $\mathrm{S} / \mathrm{N}$ ratio in the $\mathrm{OB}$, leading to cleaner, more discriminable signals exciting this olfactory center for use in higher-level processing.

\section{References}

Aroniadou-Anderjaska V, Zhou FM, Priest CA, Ennis M, Shipley MT (2000) Tonic and synaptically evoked presynaptic inhibition of sensory input to the rat olfactory bulb via $\mathrm{GABA}_{\mathrm{B}}$ heteroreceptors. J Neurophysiol 84: 1194-1203. Medline

Aston-Jones G, Bloom FE (1981) Norepinephrine-containing locus coeruleus neurons in behaving rats exhibit pronounced responses to non-noxious environmental stimuli. J Neurosci 1:887-900. Medline

Aston-Jones G, Rajkowski J, Cohen J (2000) Locus coeruleus and regulation of behavioral flexibility and attention. Prog Brain Res 126:165-182. CrossRef Medline

Berridge CW, Waterhouse BD (2003) The locus coeruleus-noradrenergic system: modulation of behavioral state and state-dependent cognitive processes. Brain Res Brain Res Rev 42:33-84. CrossRef Medline

Bouret S, Sara SJ (2002) Locus coeruleus activation modulates firing rate and temporal organization of odour-induced single-cell responses in rat piriform cortex. Eur J Neurosci 16:2371-2382. CrossRef Medline

Bouret S, Sara SJ (2004) Reward expectation, orientation of attention and locus coeruleus-medial frontal cortex interplay during learning. Eur J Neurosci 20:791-802. CrossRef Medline

Ciombor KJ, Ennis M, Shipley MT (1999) Norepinephrine increases rat mitral cell excitatory responses to weak olfactory nerve input via alpha-1 receptors in vitro. J Neurosci 90:595-606. CrossRef Medline

Cleland TA (2010) Early transformations in odor representation. Trends Neurosci 33:130-139. CrossRef Medline

Cleland TA, Linster C (2005) Computation in the olfactory system. Chem Senses 30:801-813. CrossRef Medline

Cleland TA, Morse A, Yue EL, Linster C (2002) Behavioral models of odor similarity. Behav Neurosci 116:222-231. CrossRef Medline

de Almeida L, Reiner SJ, Ennis M, Linster C (2015) Computational modeling suggests distinct, location-specific function of norepinephrine in olfactory bulb and piriform cortex. Front Comput Neurosci 9:73. CrossRef Medline

Devilbiss DM, Waterhouse BD (2004) The effects of tonic locus ceruleus output on sensory-evoked responses of ventral posterior medial thalamic and barrel field cortical neurons in the awake rat. J Neurosci 24:1077310785. CrossRef Medline

Devilbiss DM, Page ME, Waterhouse BD (2006) Locus ceruleus regulates 
sensory encoding by neurons and networks in waking animals. J Neurosci 26:9860-9872. CrossRef Medline

Devore S, Linster C (2012) Noradrenergic and cholinergic modulation of olfactory bulb sensory processing. Front Behav Neurosci 6:52. CrossRef Medline

Doucette W, Milder J, Restrepo D (2007) Adrenergic modulation of olfactory bulb circuitry affects odor discrimination. Learn Mem 14:539-547. CrossRef Medline

Eckmeier D, Shea SD (2014) Noradrenergic plasticity of olfactory sensory neuron inputs to the main olfactory bulb. J Neurosci 34:15234-15243. CrossRef Medline

Ennis M, Zhou FM, Ciombor KJ, Aroniadou-Anderjaska V, Hayar A, Borrelli E, Zimmer LA, Margolis F, Shipley MT (2001) Dopamine D2 receptormediated presynaptic inhibition of olfactory nerve terminals. J Neurophysiol 86:2986-2997. Medline

Escanilla O, Arrellanos A, Karnow A, Ennis M, Linster C (2010) Noradrenergic modulation of behavioral odor detection and discrimination thresholds in the olfactory bulb. Eur J Neurosci 32:458-468. CrossRef Medline

Escanilla O, Alperin S, Youssef M, Ennis M, Linster C (2012) Noradrenergic but not cholinergic modulation of olfactory bulb during processing of near threshold concentration stimuli. Behav Neurosci 126:720-728. CrossRef Medline

Gire DH, Schoppa NE (2008) Long-term enhancement of synchronized oscillations by adrenergic receptor activation in the olfactory bulb. J Neurophysiol 99:2021-2025. CrossRef Medline

Hasselmo ME, Linster C, Patil M, Ma D, Cekic M (1997) Noradrenergic suppression of synaptic transmission may influence cortical signal-tonoise ratio. J Neurophysiol 77:3326-3339. Medline

Hayar A, Heyward PM, Heinbockel T, Shipley MT, Ennis M (2001) Direct excitation of mitral cells via activation of alpha1-noradrenergic receptors in rat olfactory bulb slices. J Neurophysiol 86:2173-2182. Medline

Hirata A, Aguilar J, Castro-Alamancos MA (2006) Noradrenergic activation amplifies bottom-up and top-down signal-to-noise ratios in sensory thalamus. J Neurosci 26:4426-4436. CrossRef Medline

Jiang M, Griff ER, Ennis M, Zimmer LA, Shipley MT (1996) Activation of locus coeruleus enhances the responses of olfactory bulb mitral cells to weak olfactory nerve input. J Neurosci 16:6319-6329. Medline

Joëls M, Pu Z, Wiegert O, Oitzl MS, Krugers HJ (2006) Learning under stress: how does it work? Trends Cogn Sci 10:152-158. CrossRef Medline

Li G, Linster C, Cleland TA (2015) Functional differentiation of cholinergic and noradrenergic modulation in a biophysical model of olfactory bulb granule cells. J Neurophysiol 114:3177-3200. CrossRef Medline

Linster C, Nai Q, Ennis M (2011) Nonlinear effects of noradrenergic modulation of olfactory bulb function in adult rodents. J Neurophysiol 105: 1432-1443. CrossRef Medline

Mandairon N, Peace S, Karnow A, Kim J, Ennis M, Linster C (2008) Noradrenergic modulation in the olfactory bulb influences spontaneous and reward-motivated discrimination, but not the formation of habituation memory. Eur J Neurosci 27:1210-1219. CrossRef Medline

Manella LC, Alperin S, Linster C (2013) Stressors impair odor recognition memory via an olfactory bulb-dependent noradrenergic mechanism. Front Integr Neurosci 7:97. CrossRef Medline

McLean J, Waterhouse BD (1994) Noradrenergic modulation of cat area 17 neuronal responses to moving visual stimuli. Brain Res 667:83-97. CrossRef Medline

McLean JH, Shipley MT, Nickell WT, Aston-Jones G, Reyher CK (1989) Chemoanatomical organization of the noradrenergic input from locus coeruleus to the olfactory bulb of the adult rat. J Comp Neurol 285:339 349. CrossRef Medline

Moriceau S, Raineki C, Holman JD, Holman JG, Sullivan RM (2009) Enduring neurobehavioral effects of early life trauma mediated through learning and corticosterone suppression. Front Behav Neurosci 3:22. CrossRef Medline

Moxon KA, Devilbiss DM, Chapin JK, Waterhouse BD (2007) Influence of norepinephrine on somatosensory neuronal responses in the rat thalamus: a combined modeling and in vivo multi-channel, multi-neuron recording study. Brain Res 1147:105-123. CrossRef Medline

Nai Q, Dong HW, Hayar A, Linster C, Ennis M (2009) Noradrenergic regulation of GABAergic inhibition of main olfactory bulb mitral cells varies as a function of concentration and receptor subtype. J Neurophysiol 101: 2472-2484. CrossRef Medline

Nai Q, Dong HW, Linster C, Ennis M (2010) Activation of $\alpha 1$ and $\alpha 2$ noradrenergic receptors exert opposing effects on excitability of main olfactory bulb granule cells. Neuroscience 169:882-892. CrossRef Medline

Rajkowski J, Kubiak P, Aston-Jones G (1994) Locus coeruleus activity in monkey: phasic and tonic changes are associated with altered vigilance. Brain Res Bull 35:607-616. CrossRef Medline

Sandi C, Pinelo-Nava MT (2007) Stress and memory: behavioral effects and neurobiological mechanisms. Neural Plast 2007:78970. CrossRef Medline

Sara SJ (2009) The locus coeruleus and noradrenergic modulation of cognition. Nat Rev Neurosci 10:211-223. CrossRef Medline

Shea SD, Katz LC, Mooney R (2008) Noradrenergic induction of odorspecific neural habituation and olfactory memories. J Neurosci 28:1071110719. CrossRef Medline

Tan J, Savigner A, Ma M, Luo M (2010) Odor information processing by the olfactory bulb analyzed in gene-targeted mice. Neuron 65:912-926. CrossRef Medline

Valentino RJ, Van Bockstaele E (2008) Convergent regulation of locus coeruleus activity as an adaptive response to stress. Eur J Pharmacol 583:194203. CrossRef Medline

Waterhouse BD, Azizi SA, Burne RA, Woodward DJ (1990) Modulation of rat cortical area 17 neuronal responses to moving visual stimuli during norepinephrine and serotonin microiontophoresis. Brain Res 514:276292. CrossRef Medline

Waterhouse BD, Moises HC, Woodward DJ (1998) Phasic activation of the locus coeruleus enhances responses of primary sensory cortical neurons to peripheral receptive field stimulation. Brain Res 790:33-44. CrossRef Medline

Zhou FW, Dong HW, Ennis M (2016) Activation of beta-noradrenergic receptors enhances rhythmic bursting in mouse olfactory bulb external tufted cells. J Neurophysiol 116:2604-2614. CrossRef Medline 